\title{
Efficacy of Secukinumab for Moderate-to-Severe Head and Neck Psoriasis Over 52 Weeks: Pooled Analysis of Four Phase 3 Studies
}

Leon Kircik · Joseph Fowler · Jonathan Weiss $\cdot$ Xiangyi Meng •

Adriana Guana $\cdot$ Judit Nyirady

Received: May 26, 2016 / Published online: August 30, 2016

(C) The Author(s) 2016. This article is published with open access at Springerlink.com

\section{ABSTRACT}

Introduction: Psoriasis affecting the head and neck can be difficult to treat, and the presence of extensive and highly visible lesions may result in substantial psychosocial burdens. Secukinumab, a monoclonal antibody that selectively targets interleukin-17A, provides rapid and sustained clearance of moderate-to-severe psoriasis. The objective of this study was to evaluate the efficacy of secukinumab on moderate-to-severe psoriasis

Enhanced content To view enhanced content for this article go to http://www.medengine.com/Redeem/ 5785F06045D6516A.

L. Kircik $(\bowtie)$

Physicians Skin Care PLLC, Louisville, KY, USA

e-mail: wedoderm@yahoo.com

L. Kircik

Mount Sinai School of Medicine, New York, NY, USA

J. Fowler

University of Louisville, Louisville, KY, USA

J. Weiss

Gwinnett Clinical Research Center, Snellville, GA, USA

X. Meng · A. Guana · J. Nyirady

Novartis Pharmaceuticals Corporation, East

Hanover, NJ, USA affecting the head and neck. The safety and overall efficacy of secukinumab in patients with moderate-to-severe psoriasis will be described.

Methods: Data were pooled from four phase 3 studies. To be included in the head and neck analysis, patients were required to have Baseline head and neck Psoriasis Severity Area Index (PASI) scores $\geq 12$ and psoriasis covering $\geq 10 \%$ of the head and neck. Secukinumab (300 or $150 \mathrm{mg}$ ) was administered at Baseline, Weeks 1, 2 and 3 , and then every 4 weeks from Week 4 to 48.

Results: Secukinumab demonstrated high efficacy on the head and neck and the whole body. At Week 52, head and neck PASI 90/100 subscore responses were achieved by $76.0 \% / 68.7 \%$ of patients receiving secukinumab $300 \mathrm{mg}$, respectively, and by $61.4 \% / 53.1 \%$ of patients receiving secukinumab $150 \mathrm{mg}$, respectively. At Week 52, whole body composite PASI 90/100 responses were achieved by $68.1 \% / 40.8 \%$ of patients receiving secukinumab $300 \mathrm{mg}$, respectively, and by $47.6 \% / 24.3 \%$ of patients receiving secukinumab $150 \mathrm{mg}$, respectively. Secukinumab also improved Dermatology Life Quality Index scores. 
Conclusion: Secukinumab provided robust and sustained efficacy for head and neck, and whole body psoriasis, over 52 weeks, with a favorable safety profile.

Funding: Novartis Pharmaceuticals Corporation. Trial registration: ClinicalTrials.gov identifiers, NCT01365455, NCT01358578, NCT01555125, and NCT01636687.

Keywords: Head and neck psoriasis; Moderate-to-severe psoriasis; Phase 3; Plaque psoriasis; Pooled analysis; Secukinumab

\section{INTRODUCTION}

The head (including the scalp and face) and neck are the body areas most commonly affected by psoriasis, and, in many cases, the most difficult areas to treat [1-3]. Scalp psoriasis is estimated to affect between $40 \%$ and $90 \%$ of individuals with psoriasis, and facial psoriasis has been reported by $17-29 \%$ of adults with psoriasis [2, 4]. In addition to physical symptoms of itching, pain, lesion cracking, and bleeding that may cause discomfort and reduced quality of life, individuals with extensive and highly visible psoriasis affecting areas such as the head and neck can experience higher psychological burdens $[2,5,6]$. Symptoms of psoriasis can cause patients to face social stigmatization that results in embarrassment, shame, and stress [7]. Visible psoriasis can also negatively affect work or school attendance and performance, reduce self-confidence, and interfere with daily routines $[2,8]$.

The disease burden in patients with head and neck psoriasis is substantial. Patients with facial psoriasis have significantly greater whole body
Psoriasis Severity Area Index (PASI) scores than patients without facial involvement (15.6 vs. 6.9; $P<0.05)$ and facial psoriasis is associated with longer disease duration and younger age of onset $[9,10]$. Quality of life is more negatively impacted in women with scalp psoriasis, and many individuals with scalp psoriasis report being inconvenienced by caring for their scalp $[11,12]$. Additionally, scalp psoriasis has been shown to impair physical and psychological health regardless of the severity of psoriasis on other body regions [13].

Secukinumab is a human monoclonal antibody that selectively binds to and neutralizes interleukin (IL)-17A, a key cytokine in the pathogenesis of psoriasis [14]. The safety and efficacy of secukinumab has previously been demonstrated in phase 3 studies of patients with moderate-to-severe plaque psoriasis [15-18]. In this report, 52-Week results were pooled from four phase 3 studies of secukinumab in patients with moderate-to-severe psoriasis, and efficacy was evaluated for (1) head and neck (HN)PASI subscores and (2) whole body composite PASI scores. Subcomponent PASI results for the trunk, upper limbs, and lower limbs are reported separately in this publication by Menter et al. [19].

\section{METHODS}

\section{Study Design}

Data were pooled from four randomized, double-blind, placebo-controlled, parallel-group phase 3 trials [efficacy of response and safety of two fixed secukinumab regimens in psoriasis 
(ERASURE, ClinicalTrials.gov identifier, NCT01365455), full year investigative examination of secukinumab vs. etanercept using two dosing regimens to determine efficacy in psoriasis (FIXTURE, ClinicalTrials.gov identifier, NCT01358578), first study of secukinumab in pre-filled syringes in subjects with chronic plaque-type psoriasis (FEATURE, ClinicalTrials.gov identifier, NCT01555125), and judging the efficacy of secukinumab in patients with psoriasis using autoinjector (JUNCTURE, ClinicalTrials.gov identifier, NCT01636687)]. The design of these trials has been previously reported in detail [15-17]. Briefly, secukinumab or placebo was administered at Baseline, Weeks 1, 2 and 3, and then every 4 weeks from Week 4 to 48 . At Week 12, patients receiving placebo were randomized to secukinumab. Secukinumab was administered by subcutaneous injection; in ERASURE and FIXTURE the lyophilisate in vial formulation was used, in FEATURE a prefilled syringe was used, and in JUNCTURE an autoinjector was used.

\section{Study Population}

Male and female patients ( $\geq 18$ years of age) with moderate-to-severe plaque psoriasis of $\geq 6$ months' duration that was poorly controlled by topical treatments, phototherapy, and/or previous systemic therapy were considered eligible for the study population. Moderate-to-severe plaque psoriasis was defined as Baseline PASI score $\geq 12$, Investigator's Global Assessment modified 2011 (IGA mod 2011) [20] score $\geq 3$, and total body surface area (BSA) affected $\geq 10 \%$. Exclusion criteria included active, ongoing inflammatory diseases; active, ongoing, chronic or recurrent infectious disease, or evidence of active tuberculosis infection; or underlying condition significantly immunocompromising the patient and/or placing the patient at unacceptable risk for receiving an immunomodulatory therapy (e.g., lymphoproliferative disease, malignancy, history of malignancy within the past 5 years; past medical history of HIV, hepatitis B, or hepatitis C). To be included in the head and neck subanalysis, patients had to have a PASI score $\geq 12$ for the head and neck region and have psoriasis covering $\geq 10 \%$ of the BSA of the head and neck region. Composite PASI scores are calculated as a weighted average of PASI scores for the head and neck, upper limbs, trunk, and lower limbs using multipliers of $0.1,0.2,0.3$, and 0.4, respectively, to account for the relative percentage of total BSA these regions make up. Scores for each body region are calculated as the affected area (A) score multiplied by the sum of erythema (E), induration (I), and desquamation (D) scores for that body region.

\section{Efficacy and Safety Assessments}

Co-primary efficacy variables in all four trials were PASI 75 response rates and IGA mod 2011 $0 / 1$ response rates at Week 12 . PASI 90 response rate at Week 12 was a key secondary endpoint in all trials. PASI 100 response rates at Week 12 and achievement of dermatology life quality index (DLQI) [21] scores of $0 / 1$, representing little or no effect of psoriasis on patient quality of life, were also measured. Safety and tolerability assessments included vital signs, clinical laboratory variables, electrocardiograms, and adverse event (AE) monitoring. Week 52 safety data were pooled from all 4 studies.

\section{Statistical Analysis}

Data from ERASURE, FIXTURE, FEATURE, and JUNCTURE were pooled to assess long-term efficacy through Week 52. Missing values were 
imputed by multiple imputation (MI), in which missing data are replaced by values derived from large data sets of possible values. The SAS (version 9.3, SAS Institute, Cary, NC, USA) MI procedure was used to generate data sets for 500 imputations. Results are presented by MI because this method more accurately reflects response rates observed in a clinical setting than the more conservative non-responder imputation method, which underestimates PASI responses [22]. Efficacy results are presented for the full analysis set of patients, which is defined as all patients to whom study treatment had been assigned. Safety results are presented for the safety set of patients, which is defined as all patients who took at least one dose of study treatment during the treatment period and who had at least one Post-Baseline safety assessment. This article is based on previously conducted studies, and does not involve any new studies of human or animal subjects performed by any of the authors.

\section{RESULTS}

\section{Patient Demographics}

Treatment groups were well balanced for demographic and Baseline disease characteristics in the overall study population (Table 1). Baseline disease characteristics were representative of the target population with moderate-to-severe plaque psoriasis. The mean age of patients at Baseline was 45 years, and approximately $70 \%$ of participants were White men. Patients had a mean body weight of approximately $86 \mathrm{~kg}$ and a mean body mass index of approximately $29 \mathrm{~kg} / \mathrm{m}^{2}$. Disease severity was comparable across treatment groups. Mean PASI scores at Baseline were 22.7 for patients receiving secukinumab $300 \mathrm{mg}$,
22.8 for patients receiving secukinumab $150 \mathrm{mg}$, and 22.5 for patients receiving placebo.

\section{Head and Neck Efficacy}

Treatment with secukinumab $300 \mathrm{mg}$ and secukinumab $150 \mathrm{mg}$ resulted in rapid and sustained skin clearance on the head and neck. For secukinumab $300 \mathrm{mg}$, initial HNPASI 75,90 , and 100 response rates were maintained to Week 52. At Week 16, 82.4\% and $72.2 \%$ of patients receiving secukinumab $300 \mathrm{mg}$ had HNPASI 90 and HNPASI 100 responses, respectively. At Week 52, HNPASI 90 and HNPASI 100 response rates were achieved by $76.0 \%$ and $68.7 \%$, respectively, of patients receiving secukinumab $300 \mathrm{mg}$. With secukinumab $150 \mathrm{mg}$, HNPASI 90 and 100 response rates were achieved by $69.9 \%$ and $57.7 \%$ of patients at Week 16 , respectively and by $61.4 \%$ and $53.1 \%$ of patients at Week 52 , respectively (Fig. 1). A 50\% reduction in mean HNPASI score occurred after 2.0 weeks (95\% confidence interval $[\mathrm{CI}] 1.9,2.2)$ with secukinumab $300 \mathrm{mg}$ and after 2.7 weeks (95\% CI 2.6, 2.9) with secukinumab $150 \mathrm{mg}$ (Fig. 2).

\section{Whole Body Efficacy}

Pooled efficacy responses through Week 52 from these four phase 3 trials are presented in Fig. 3. In the overall pooled study population, secukinumab provided rapid skin clearance with responses being observed as early as Week 1. Initial responses were maintained to Week 52 and the greatest benefit was observed with secukinumab $300 \mathrm{mg}$. At Week 52, PASI 90 and PASI 100 were achieved by $68.1 \%$ and $40.8 \%$ of patients receiving secukinumab $300 \mathrm{mg}$, respectively, and by $47.6 \%$ and $24.3 \%$ of patients receiving secukinumab $150 \mathrm{mg}$, respectively. 
Table 1 Patient demographics and Baseline disease characteristics (overall population)

\begin{tabular}{|c|c|c|c|}
\hline & $\begin{array}{l}\text { Secukinumab } 300 \mathrm{mg} \\
(n=691)\end{array}$ & $\begin{array}{l}\text { Secukinumab } 150 \mathrm{mg} \\
(n=692)\end{array}$ & $\begin{array}{l}\text { Placebo } \\
(n=692)\end{array}$ \\
\hline Gender (male), $n$ (\%) & $477(69.0)$ & $485(70.1)$ & $484(69.9)$ \\
\hline Age (years), mean (SD) & $44.9(13.3)$ & $45.1(13.4)$ & $44.7(12.8)$ \\
\hline Range & $18-83$ & $18-83$ & $18-82$ \\
\hline \multicolumn{4}{|l|}{ Race, $n(\%)$} \\
\hline White & $505(73.1)$ & $499(72.1)$ & $509(73.6)$ \\
\hline Asian & $129(18.7)$ & $129(18.6)$ & $121(17.5)$ \\
\hline Black & $9(1.3)$ & $13(1.9)$ & $13(1.9)$ \\
\hline Other & $48(6.9)$ & $51(7.4)$ & $49(7.1)$ \\
\hline Height $(\mathrm{cm})$, mean $(\mathrm{SD})^{\mathrm{a}}$ & $171.2(9.6)$ & $171.3(10.2)$ & $171.6(10.2)$ \\
\hline Range & $145.0-198.5$ & $145.0-197.0$ & $141.0-200.7$ \\
\hline Weight $(\mathrm{kg})$, mean $(\mathrm{SD})$ & $86.6(23.2)$ & $86.6(23.2)$ & $86.0(22.6)$ \\
\hline Range & $45.0-219.1$ & $43.1-215.0$ & $42.0-191.9$ \\
\hline BMI $\left(\mathrm{kg} / \mathrm{m}^{2}\right)$, mean $(\mathrm{SD})^{\mathrm{a}}$ & $29.4(6.9)$ & $29.4(7.0)$ & $29.1(6.9)$ \\
\hline Range & $17.4-67.4$ & $16.5-79.7$ & $16.2-71.2$ \\
\hline PASI score, mean $(\mathrm{SD})$ & $22.7(9.4)$ & $22.8(10.0)$ & $22.5(9.7)$ \\
\hline Range & $11.2-72.0$ & $12.0-69.6$ & $10.6-72.0$ \\
\hline \multicolumn{4}{|l|}{ IGA modified 2011 score, $n$ (\%) } \\
\hline 3 (Moderate disease) & $436(63.1)$ & $439(63.4)$ & $424(61.3)$ \\
\hline 4 (Severe disease) & $255(36.9)$ & $253(36.6)$ & $268(38.7)$ \\
\hline Time since first psoriasis diagnosis $(\mathrm{y})$, mean $(\mathrm{SD})$ & $17.0(12.0)$ & $17.9(12.5)$ & $17.5(12.2)$ \\
\hline Range & $0.5-61.5$ & $0.5-69.0$ & $0.5-68.1$ \\
\hline $\begin{array}{l}\text { Previous exposure to systemic psoriasis therapy }{ }^{\mathrm{b}} \\
\quad \text { (yes), } n(\%)\end{array}$ & $438(63.4)$ & $447(64.6)$ & $420(60.7)$ \\
\hline $\begin{array}{l}\text { Previous exposure to biologic systemic psoriasis } \\
\text { therapy } \mathrm{b}^{\mathrm{b}} \text { (yes), } n(\%)\end{array}$ & $146(21.1)$ & $161(23.3)$ & $147(21.2)$ \\
\hline $\begin{array}{l}\text { Previous exposure to non-biologic systemic psoriasis } \\
\text { therapy }^{\mathrm{b}} \text { (yes), } n \text { (\%) }\end{array}$ & $373(54.0)$ & $393(56.8)$ & $363(52.5)$ \\
\hline
\end{tabular}

Results are for the full analysis set of patients

$B M I$ body mass index, $B S A$ body surface area, IGA investigator's global assessment, $P A S I$ psoriasis area and severity index, $S D$ standard deviation

a $n=688$ for secukinumab $300 \mathrm{mg}, n=692$ for secukinumab $150 \mathrm{mg}$

b $n=690$ for secukinumab $300 \mathrm{mg}$ 


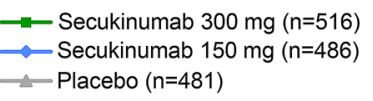

(a) HNPASI 75

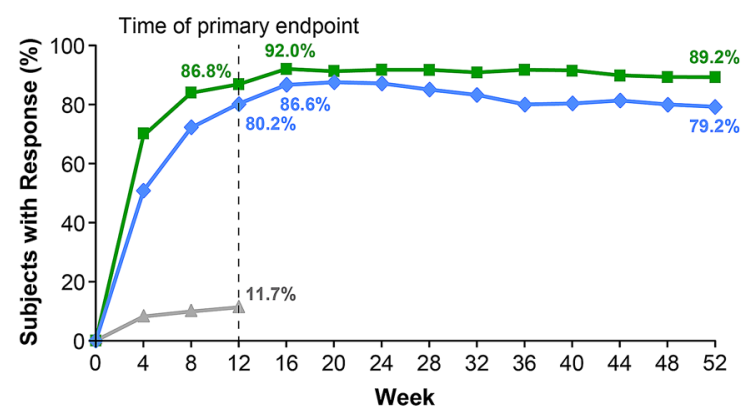

(b) HNPASI 90

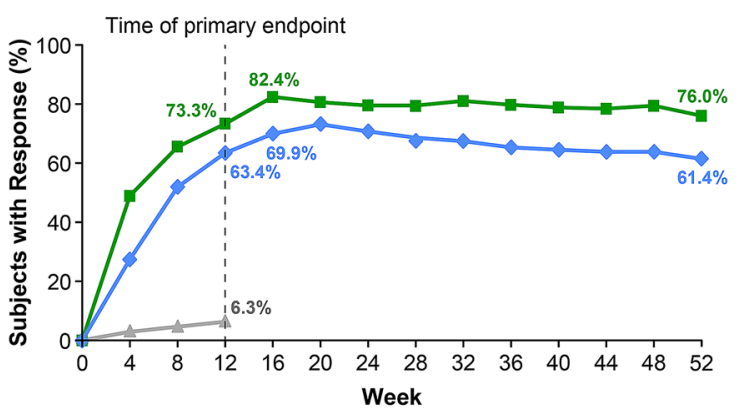

(c) HNPASI 100

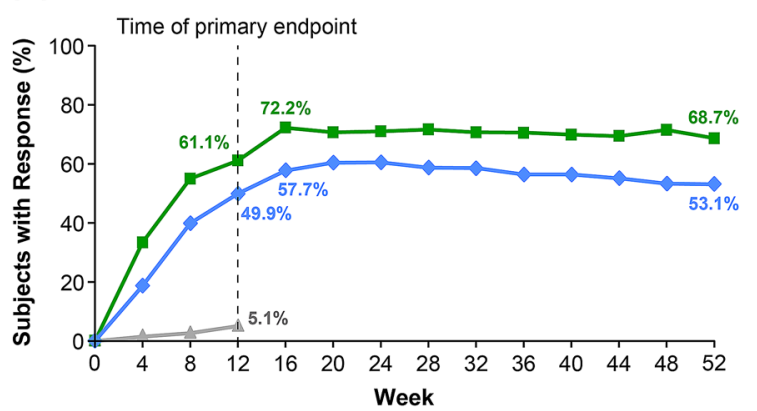

Fig. 1 Efficacy of secukinumab on the head and neck over time. Missing values were imputed by multiple imputation. Clinical response rates for a HNPASI 75, b HNPASI 90, and c HNPASI 100 from Baseline to Week 52.

Treatment with secukinumab also showed rapid and significant improvement in quality of life as measured by DLQI. At Week 12, DLQI scores of 0 or 1 were achieved by $58.8 \%$ of patients receiving secukinumab $300 \mathrm{mg}$ and $50.1 \%$ of patients receiving secukinumab $150 \mathrm{mg}$. Improvements in DLQI continued to Week 52 with DLQI scores of 0 or 1 being achieved by $67.9 \%$ and $53.7 \%$ of patients receiving secukinumab $300 \mathrm{mg}$ and secukinumab $150 \mathrm{mg}$, respectively. Mean decreases (improvements) in DLQI from Baseline to Week 52 were -11.0 with secukinumab $300 \mathrm{mg}$ and -9.2 with secukinumab $150 \mathrm{mg}$, and these responses surpassed the $\geq 5$-point reduction in DLQI required for a minimal clinically important $n$ represents the number of evaluable subjects. HNPASI 75/90/100, 75\%/90\%/100\% improvement from Baseline head and neck psoriasis area and severity index scores

difference in patients with psoriasis that are receiving biologic therapy [23].

\section{Safety}

Secukinumab demonstrated a favorable safety profile in the overall pooled study population, and the rates of AEs were similar between the 300 and $150 \mathrm{mg}$ doses (Table 2). Through Week 52 , AEs were reported in $83.3 \%$ of patients receiving secukinumab $300 \mathrm{mg}$ and in $81.2 \%$ of patients receiving secukinumab $150 \mathrm{mg}$. The most common AEs for both secukinumab doses were nasopharyngitis (23.7-24.9\%), headache (9.4-11.4\%), diarrhea (6.5-7.8\%), and upper respiratory tract infection (7.7-9.2\%). Serious 


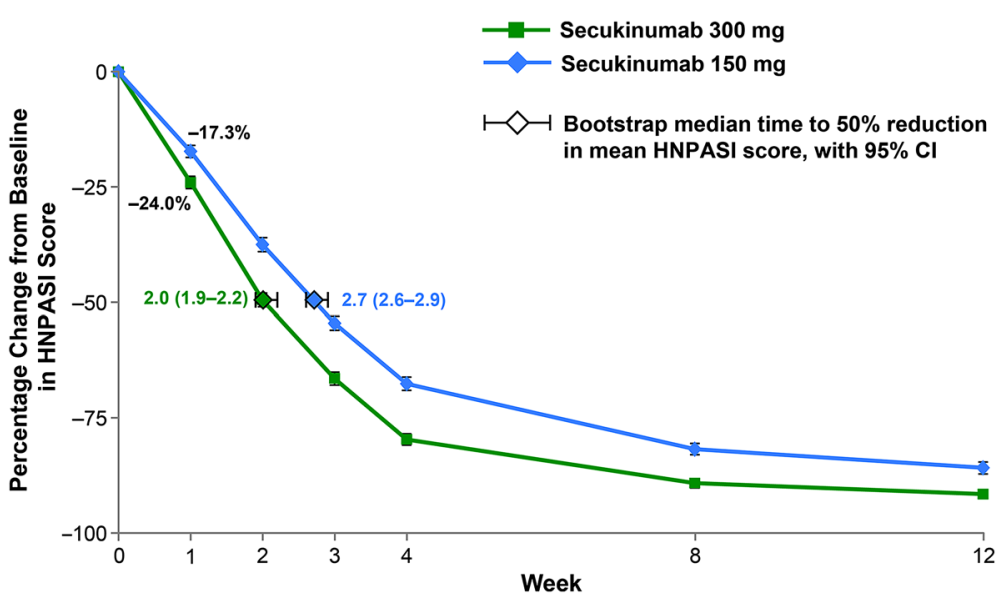

Fig. 2 Percent change in mean HNPASI score over time. A repeated-measure, mixed-effects model was used to analyze the mean percent change from Baseline in PASI score. The median time to a $50 \%$ reduction in mean
HNPASI score was estimated from parametric bootstrap samples with the use of linear interpolation between time points. CI confidence interval, HNPASI head and neck psoriasis area severity index

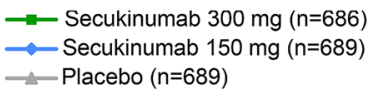

(a) PASI 75

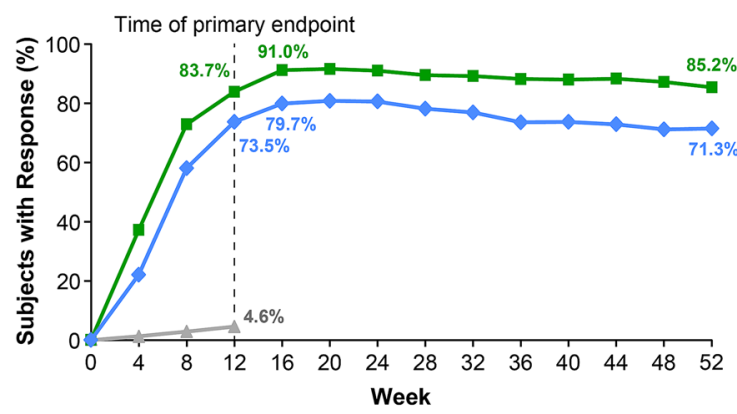

(c) PASI 100

\section{(b) PASI 90}

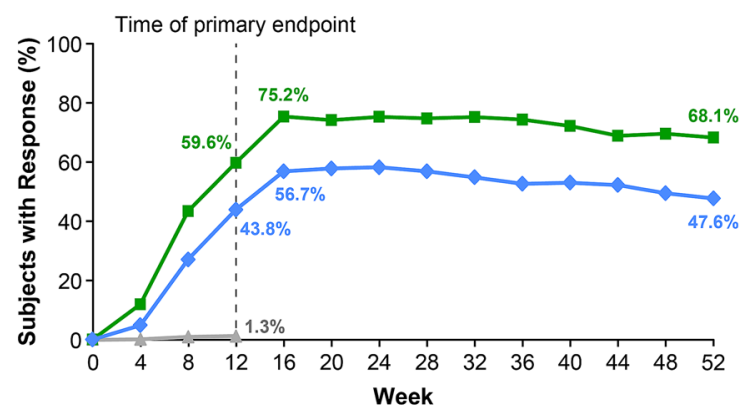

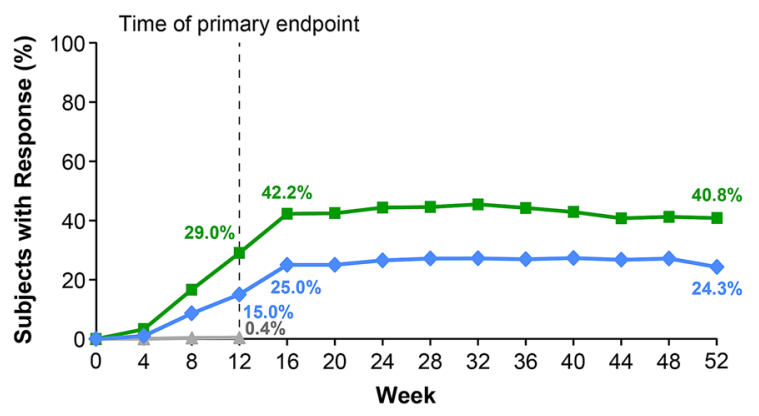

Fig. 3 Efficacy of secukinumab on the whole body over time. Missing values were imputed by multiple imputation. Clinical response rates for a PASI 75, b PASI 90, and c PASI 100 from Baseline to Week 52. PASI 75/90/100, $75 \% / 90 \% / 100 \%$ improvement from Baseline psoriasis area and severity index scores 
Table 2 Summary of adverse events

\begin{tabular}{|c|c|c|c|}
\hline \multirow[t]{2}{*}{ Preferred term, $n(\%)$} & \multicolumn{2}{|l|}{52 Weeks } & \multirow{2}{*}{$\begin{array}{l}12 \text { Weeks } \\
\text { Placebo } \\
(n=694)\end{array}$} \\
\hline & $\begin{array}{l}\text { Secukinumab } 300 \mathrm{mg} \\
(n=690)\end{array}$ & $\begin{array}{l}\text { Secukinumab } 150 \mathrm{mg} \\
(n=692)\end{array}$ & \\
\hline $\begin{array}{l}\text { Discontinuation due to adverse } \\
\text { event }\end{array}$ & $21(3.0)$ & $25(3.6)$ & $9(1.3)$ \\
\hline Any serious adverse event & $48(7.0)$ & $48(6.9)$ & $12(1.7)$ \\
\hline Any adverse event & $575(83.3)$ & $562(81.2)$ & $340(49.0)$ \\
\hline \multicolumn{4}{|l|}{ Most common adverse events (>5\%) } \\
\hline Nasopharyngitis & $172(24.9)$ & $164(23.7)$ & $60(8.6)$ \\
\hline Headache & $79(11.4)$ & $65(9.4)$ & $36(5.2)$ \\
\hline Diarrhea & $54(7.8)$ & $45(6.5)$ & $10(1.4)$ \\
\hline Upper respiratory tract infection & $53(7.7)$ & $64(9.2)$ & $5(0.7)$ \\
\hline Cough & $45(6.5)$ & $21(3.0)$ & $9(1.3)$ \\
\hline Back pain & $37(5.4)$ & $30(4.3)$ & $10(1.4)$ \\
\hline Hypertension & $35(5.1)$ & $37(5.3)$ & $12(1.7)$ \\
\hline Arthralgia & $34(4.9)$ & $38(5.5)$ & $17(2.4)$ \\
\hline
\end{tabular}

Results are for the safety set of patients. Safety results are only presented to Week 12 for placebo because at Week 12, patients receiving placebo were randomized to secukinumab

AEs were reported in $7.0 \%$ of patients receiving secukinumab $300 \mathrm{mg}$ and in $6.9 \%$ of patients receiving secukinumab $150 \mathrm{mg}$. Discontinuation of secukinumab due to AEs occurred in $3.0 \%$ of patients receiving secukinumab $300 \mathrm{mg}$ and in $3.6 \%$ of patients receiving secukinumab $150 \mathrm{mg}$.

\section{DISCUSSION}

The efficacy of secukinumab $300 \mathrm{mg}$ and secukinumab $150 \mathrm{mg}$ was previously demonstrated to be superior to placebo (in ERASURE, FIXTURE, FEATURE, and JUNCTURE) and etanercept (in FIXTURE) at Week 12 [15-17]. Results from this pooled analysis of four phase 3 trials show that secukinumab is effective for the treatment of moderate-to-severe psoriasis affecting the head and neck, and the whole body. Secukinumab therapy resulted in rapid improvement of psoriasis on the head and neck. Improvements were observed as early as Week 1 at which point secukinumab $300 \mathrm{mg}$ provided an approximate $25 \%$ reduction in mean HNPASI score from Baseline. Disease clearance continued to increase on the head and neck after the first Week, and patients experienced a 50\% reduction in mean HNPASI score after 2.0 weeks of treatment with secukinumab $300 \mathrm{mg}$. Improvement in psoriasis affecting the head and neck were maintained through Week 52, with the greatest benefit seen in patients receiving secukinumab $300 \mathrm{mg}$ (Fig. 1).

The efficacy and safety of secukinumab was consistent across all four phase 3 trials that were pooled for this analysis. Results from this study are also consistent with findings from other studies that evaluated the efficacy of biologic 
agents by body region [24-26]. In these studies, along with the findings reported here, head and neck plaque psoriasis generally responded favorably, rapidly, and significantly to biologic treatment. Conversely, psoriasis on the head and neck does not typically respond well to conventional systemic therapies, and topical therapies can be burdensome to apply resulting in low adherence [26, 27]. This study was limited by the inability to differentiate between affected areas of the head and neck (e.g., scalp vs face psoriasis) because PASI does not allow for differentiation of specific regions of the head and neck. A study is currently ongoing that will evaluate the efficacy of secukinumab on scalp psoriasis, and results from this trial will provide further data on the treatment of this difficult to manage area [28]. Additionally, there was no control group after Week 12.

Results of this pooled analysis demonstrate that secukinumab is an effective and well-tolerated treatment for plaque psoriasis of the head and neck. The majority of the patients treated with secukinumab $300 \mathrm{mg}$ achieved almost clear or clear skin as indicated by high HNPASI 90 and HNPASI 100 response rates. Secukinumab also provided robust overall efficacy. At Week 12, PASI 75 response rates were similar between the head and neck region and the whole body. A larger proportion of patients receiving secukinumab $300 \mathrm{mg}$ achieved HNPASI 90 and HNPASI 100 (73.3\% and $61.1 \%$, respectively) response rates at Week 12 than achieved composite PASI 90 and PASI 100 (59.6\% and 29.0\%, respectively) response rates over the same time period. These findings indicate that patients achieve complete or almost complete clearance of psoriasis on the head and neck at a quicker rate than on the whole body following treatment with secukinumab. Likewise, at Week 52, HNPASI response rates were numerically greater than composite PASI response rates. With secukinumab $300 \mathrm{mg}$,
HNPASI 90 and HNPASI 100 responses were achieved by $76.0 \%$ and $68.7 \%$ of patients, respectively, compared with composite PASI 90 and PASI 100 response rates of $68.1 \%$ and $40.8 \%$, respectively. It is important to note that achievement of a PASI 100 response for a particular body region is easier than achievement of the same response for the whole body because full clearance across all body regions is not required. The rapid and sustained clearance of psoriasis from the head and neck with secukinumab may provide patients with a meaningful improvement in areas of the body that are associated with a large psychosocial burden.

In the overall pooled analysis population, disease clearance was associated with improvement in quality of life for patients receiving secukinumab. In ERASURE and FIXTURE, findings from the Psoriasis Symptom Diary ${ }^{\circ}$ indicate that improvements in PASI response rates are paralleled by significant reductions in patient-reported symptoms of itching, pain, and scaling [29]. Additionally, improvements in DLQI at Week 52 with secukinumab were sufficient to meet the definition of a clinically important difference in health-related quality of life for patients with psoriasis who are receiving biologic therapy [23]. The importance of such improvement in DLQI should be highlighted because it is an indicator of patient satisfaction with therapy and likely leads to stronger adherence and better clinical outcomes.

\section{CONCLUSION}

Pooled results of four phase 3 studies of secukinumab showed robust and sustained efficacy in treating psoriasis affecting both the head and neck and the whole body. 


\section{ACKNOWLEDGMENTS}

Previously presented in part at the American Academy of Dermatology (AAD) Annual Meeting, San Francisco, California, United States, 20-24 March 2015. Editorial assistance in the preparation of this manuscript was provided by Oxford PharmaGenesis Inc. Support for this assistance was funded by Novartis Pharmaceuticals Corporation. Sponsorship and article processing charges were funded by Novartis Pharmaceuticals Corporation. All authors had full access to all of the data in this study and take complete responsibility for the integrity of the data and accuracy of the data analysis. All named authors meet the International Committee of Medical Journal Editors (ICMJE) criteria for authorship for this manuscript, take responsibility for the integrity of the work as a whole, and have given final approval to the version to be published. The authors received no financial support or other form of compensation related to the development of this manuscript

Disclosures. Leon Kircik has served as a consultant and/or speaker and received honoraria from Abbott, Aclaris, Allergan, Amgen, Anacor Pharmaceuticals, Assos, Astellas, Biogen-Idec, Colbar, Celgene, Colla Genex, Connetics Corporation, Dermik Laboratories, Embil Pharmaceuticals, EOS, Ferndale Laboratories, Galderma, Genentech, Intendis, Innocutis, Innovail, Johnson \& Johnson, Laboratory Skin Care, Leo, L'Oreal, $3 \mathrm{M}$, Medical International Technologies, Merck, Merz, Nano Bio, Novartis, Onset, OrthoNeutrogena, Promius, PediaPharma, PharmaDerm, PuraCap, Quinnova, Serono, SkinMedica, Stiefel Laboratories, Taro, Triax, UCB, Valeant Pharmaceuticals,
Warner-Chilcott, and ZAGE. Dr. Kircik has also served as an investigator and received research grants from Acambis, Allergan, Amgen, Anacor Pharmaceuticals, Astellas, Asubio, Berlex Laboratories, Biolife, Biopelle, Boehringer-Ingelheim, Breckinridge Pharma, Celgene, Centocor, CollaGenex, Combinatrix, Connetics Corporation, Coria, Dermira, Dow Pharmaceutical Sciences, Dusa, Eli Lilly, Ferndale Laboratories, Galderma, Genentech, GlaxoSmithKline, Health Point, Idera, Intendis, Johnson \& Johnson, Leo, L'Oreal, $3 \mathrm{M}$, Maruho, Medicis Pharmaceuticas Corp, Nano Bio, Novartis, Noven Pharmaceuticals, Nucryst Pharmaceuticals Corp, Obagi, Onset, OrthoNeutrogena, Promius, QLT, PharmaDerm, Pfizer, Quinnova, Quatrix, SkinMedica, Stiefel Laboratories, Toler Rx, UCB, Valeant Pharmaceuticals, Warner-Chilcott, and XenoPort. Dr. Kircik holds stock in Johnson \& Johnson. Joseph Fowler has served as a consultant and/or speaker and received honoraria from Bayer, Galderma, GSK, Innocutis, Johnson \& Johnson, Quinnova, Ranbaxy, and SmartPractice. Dr. Fowler has also served as an investigator and received research grants from $3 \mathrm{M}$, Abbot, Allergan, Amgen, Anacor, Astelles, Celgene, Centocor-Janssen, Chugai, Dermik, Galderma, Johnson \& Johnson, Lilly, Medicis-Valeant, Merck, Novartis, OnSet, Pfizer, Quinnova, SmartPractice, Taisho, Taro, and Valeant. Jonathan Weiss has served as a consultant and received honoraria from Celgene, Galderma, Leo, Promius and Valeant. Dr. Weiss has also served as an investigator and received research grants from Allergan, Amgen, Celgene, Galderma, Leo, Novartis, Promius, Valeant and, Xenoport. Xiangyi Meng is an employee of Novartis. Adriana Guana is an employee of Novartis. Judit Nyirady is an employee of Novartis. 
Compliance with Ethics Guidelines. This article is based on previously conducted studies, and does not involve any new studies of human or animal subjects performed by any of the authors.

Open Access. This article is distributed under the terms of the Creative Commons Attribution-NonCommercial 4.0 International License (http://creativecommons.org/licenses/ by-nc/4.0/), which permits any noncommercial use, distribution, and reproduction in any medium, provided you give appropriate credit to the original author(s) and the source, provide a link to the Creative Commons license, and indicate if changes were made.

\section{REFERENCES}

1. Papp K, Berth-Jones J, Kragballe K, Wozel G, de la Brassinne M. Scalp psoriasis: a review of current topical treatment options. J Eur Acad Dermatol Venereol. 2007;21:1151-60.

2. Crowley J. Scalp psoriasis: an overview of the disease and available therapies. J Drugs Dermatol. 2010;9:912-8.

3. Kragballe K. Management of difficult to treat locations of psoriasis. scalp, face, flexures, palm/soles and nails. Curr Probl Dermatol. 2009;38:160-71.

4. van de Kerkhof PC, Murphy GM, Austad J, Ljungberg A, Cambazard F, Duvold LB. Psoriasis of the face and flexures. J Dermatolog Treat. 2007; 18:351-60.

5. Mattei PL, Corey KC, Kimball AB. Cumulative life course impairment: evidence for psoriasis. Curr Probl Dermatol. 2013;44:82-90.

6. Kimball AB, Jacobson C, Weiss S, Vreeland MG, Wu Y. The psychosocial burden of psoriasis. Am J Clin Dermatol. 2005;6:383-92.

7. Raho G, Koleva DM, Garattini L, Naldi L. The burden of moderate to severe psoriasis: an overview. Pharmacoeconomics. 2012;30:1005-13.

8. Young M. The psychological and social burdens of psoriasis. Dermatol Nurs. 2005;17:15-9.
9. Young Park J, Hyun Rim J, Beom Choe Y, Il Youn J. Facial psoriasis: comparison of patients with and without facial involvement. J Am Acad Dermatol. 2004;50:582-4.

10. Canpolat F, Cemil BC, Eskioglu F, Akis HK. Is facial involvement a sign of severe psoriasis? Eur J Dermatol. 2008;18:169-71.

11. Chen SC, Yeung J, Chren MM. Scalpdex: a quality-of-life instrument for scalp dermatitis. Arch Dermatol. 2002;138:803-7.

12. Sampogna F, Linder D, Piaserico S, Altomare G, Bortune M, Calzavara-Pinton P, et al. Quality of life assessment of patients with scalp dermatitis using the Italian version of the Scalpdex. Acta Derm Venereol. 2014;94:411-4.

13. Zampieron A, Buja A, Fusco M, Linder D, Bortune M, Piaserico S, et al. Quality of life in patients with scalp psoriasis. G Ital Dermatol Venereol. 2015;150:309-16.

14. Lynde CW, Poulin Y, Vender R, Bourcier M, Khalil S. Interleukin 17A: toward a new understanding of psoriasis pathogenesis. J Am Acad Dermatol. 2014;71:141-50.

15. Langley RG, Elewski BE, Lebwohl M, Reich K, Griffiths CE, Papp K, et al. Secukinumab in plaque psoriasis-results of two phase 3 trials. N Engl J Med. 2014;371:326-38.

16. Blauvelt A, Prinz JC, Gottlieb AB, Kingo K, Sofen H, Ruer-Mulard $\mathrm{M}$, et al. Secukinumab administration by pre-filled syringe: efficacy, safety, and usability results from a randomized controlled trial in psoriasis (FEATURE). $\mathrm{Br} \mathrm{J}$ Dermatol. 2015;172:484-93.

17. Paul C, Lacour JP, Tedremets L, Kreutzer K, Jazayeri S, Adams S, et al. Efficacy, safety and usability of secukinumab administration by autoinjector/pen in psoriasis: a randomized, controlled trial (JUNCTURE). J Eur Acad Dermatol Venereol. 2015;29:1082-90.

18. Thaçi D, Blauvelt A, Reich $\mathrm{K}$, Tsai TF, Vanaclocha F, Kingo $\mathrm{K}$, et al. Secukinumab is superior to ustekinumab in clearing skin of subjects with moderate to severe plaque psoriasis: CLEAR, a randomized controlled trial. J Am Acad Dermatol. 2015;73:400-9.

19. Menter A, Cather JC, Jarratt M, Meng X, Guana A, Nyirady J. Efficacy of secukinumab on moderate-to-severe plaque psoriasis affecting different body regions: a pooled analysis of four phase 3 studies. Dermatol Ther (Heidelb). 2016. doi:10.1007/s13555-016-0140-7. (Online first). 
20. Langley RG, Feldman SR, Nyirady J, van de Kerkhof $\mathrm{P}$, Papavassilis C. The 5-point Investigator's Global Assessment (IGA) Scale: a modified tool for evaluating plaque psoriasis severity in clinical trials. J Dermatol Treat. 2015;26:23-31.

21. Finlay AY, Khan GK. Dermatology life quality index (DLQI) - a simple practical measure for routine clinical use. Clin Exp Dermatol. 1994;19:210-6.

22. Langley RG, Reich K, Papavassilis C, Fox T, Gong Y, Güttner A. Multiple imputation methodology is reflective of secukinumab efficacy in real clinical practice: data from the FIXTURE and ERASURE studies in moderate-to-severe plaque psoriasis (abstract). Br J Dermatol. 2014;171:e165 (Abstract P199).

23. Katugampola RP, Lewis VJ, Finlay AY. The dermatology life quality index: assessing the efficacy of biological therapies for psoriasis. $\mathrm{Br} \mathrm{J}$ Dermatol. 2007;156:945-50.

24. Kalb RE, Blauvelt A, Sofen HL, Chevrier M, Amato $\mathrm{D}$, Calabro $\mathrm{S}$, et al. Effect of infliximab on health-related quality of life and disease activity by body region in patients with moderate-to-severe psoriasis and inadequate response to etanercept: results from the PSUNRISE trial. J Drugs Dermatol. 2013;12:874-80.

25. Griffiths CE, Sterry W, Brock F, Dilleen M, Stefanidis D, Germain JM, et al. Pattern of response in patients with moderate-to-severe psoriasis treated with etanercept. $\mathrm{Br} \mathrm{J}$ Dermatol. 2015;172:230-8.

26. Navarini AA, Poulin Y, Menter A, Gu Y, Teixeira HD. Analysis of body regions and components of PASI scores during adalimumab or methotrexate treatment for patients with moderate-to-severe psoriasis. J Drugs Dermatol. 2014;13:554-62.

27. Menter A, Korman NJ, Elmets CA, Feldman SR, Gelfand JM, Gordon KB, et al. Guidelines of care for the management of psoriasis and psoriatic arthritis: section 6. Guidelines of care for the treatment of psoriasis and psoriatic arthritis: case-based presentations and evidence-based conclusions. J Am Acad Dermatol. 2011;65:137-74.

28. Efficacy and safety of subcutaneous secukinumab in adults with moderate to severe scalp psoriasis (SCALP): ClinicalTrials.gov. Available from https:// clinicaltrials.gov/ct2/show/NCT02267135. Accessed 14 Jan 2016.

29. Strober B, Sigurgeirsson B, Popp G, Sinclair R, Krell $\mathrm{J}$, Stonkus $\mathrm{S}$, et al. Secukinumab improves patient-reported psoriasis symptoms of itching, pain, and scaling: results of two phase 3, randomized, placebo-controlled clinical trials. Int J Dermatol. 2016;55:401-7. 